\title{
A Rare Case of Multiple Internal Root Resorption after the Delayed Treatment of a Traumatic Injury: A Case Report
}

\author{
Dan Henry Levy ${ }^{1}$, Sarit Rozenfeld ${ }^{2}$, Joe Ben Itzhak ${ }^{3}$, Meital Abadi ${ }^{4}$, Yoav Shapinko ${ }^{5}$, Michael Solomonov ${ }^{6}$
}

\begin{abstract}
Aim: The objective of this case report was to present a rare case of simultaneous multiple internal root resorption (IRR) in four mandibular incisors and discuss the possible etiology and suitable armamentarium for its treatment based on different morphological considerations.

Background: IRR in permanent dentition is a rare pathological condition and its etiology is not yet fully understood. Very few cases of multiple IRR were reported. This is the first reported case of multiple IRR due to traumatic injury.

Case description: A 23-year-old man suffered trauma to his mandible after falling from a trampoline. His mandibular incisors suffered subluxation injuries and his orthodontic fixed retainer got detached. He delayed treatment and visited our clinic 4.5 months after the incident. Clinical and radiographic examination revealed four mandibular incisors with almost identical IRR defects at the apical third of the roots. The patient was then treated with four non-surgical root canal treatments using various endodontic instruments and techniques. Fifteen-month post-trauma, he showed no evidence of pathology at the follow-up examination.

Conclusion: Delayed treatment of dental trauma might cause multiple IRR, and the presence of an orthodontic fixed retainer can distribute surface forces and result in uniform IRR defects.

Clinical significance: The combination of the self-adjusting file (SAF) and the XP-endo finisher is recommended for chemomechanical preparation of IRR defects in oval canals, especially at the apical third.

Keywords: Case report, Case-specific armamentarium, Delayed treatment, Dental trauma, Multiple internal root resorption.

The Journal of Contemporary Dental Practice (2021): 10.5005/jp-journals-10024-3041
\end{abstract}

\section{BACKGROUND}

Root resorption is a condition associated with either a physiologic or pathologic process that results in the loss of hard dental tissues or bone. Internal root resorption (IRR) is transient or progressive resorption, mostly confined to the intraradicular space, carried out by multinucleated clastic cells, and is preceded by chronic inflammation. ${ }^{2,3}$ Most of the current knowledge on IRR is based on case reports. IRR in the permanent dentition is a rare pathological condition and its etiology remains poorly understood, although it is mostly agreed upon that it is probably the result of some form of damage to the protective layer of odontoblasts and predentin. ${ }^{4-8}$

Trauma is considered the most common cause for the initiation of resorption. Other possible causes are inflammations due to deep caries lesions, excessive heat during dental treatment, orthodontic or periodontal treatment, auto-transplantation, and calcium hydroxide application ${ }^{4-7}$ Idiopathic IRR was also reported. ${ }^{5,9}$

Coronally to the active IRR area, the pulp is usually necrotic while apically the pulp remains vital and supplies nutrients to the clastic cells. If the apical pulp loses its vitality, the resorptive process stops. $^{10}$

The following is a rare case in which all four mandibular incisors underwent simultaneous IRR at the apical third of their roots within 4.5 months after dental trauma.

The purpose of this case report was to discuss the relationship between trauma, orthodontic treatment, and IRR and to present the suggested armamentarium for such cases.

\begin{abstract}
1-3,6 Department of Endodontics, Israel Defense Forces (IDF) Medical Corps, Tel HaShomer, Israel

${ }^{4}$ Department of prosthodontics, Israel Defense Forces (IDF) Medical Corps, Tel HaShomer, Israel

${ }^{5}$ Department of orthodontics, Maurice and Gabriella Goldshleger School of Dental Medicine, Tel Aviv University, Tel Aviv, Israel

Corresponding Author: Dan Henry Levy, Department of Endodontics, Israel Defense Forces (IDF) Medical Corps, Tel HaShomer, Israel, Phone: +972 6219515, Fax: +972 37377178, e-mail: Danhenry@post.bgu.ac.il

How to cite this article: Levy DH, Rozenfeld S, Itzhak JB, et al. A Rare Case of Multiple Internal Root Resorption after the Delayed Treatment of a Traumatic Injury: A Case Report. J Contemp Dent Pract 2021;22(2):194-197.
\end{abstract}

Source of support: Nil

Conflict of interest: None

\section{Case Description}

A 23-year-old man in generally good health came independently to our endodontic department. He reported suffering dental trauma 4.5 months ago as a result of his knee hitting his lower jaw due to falling from a trampoline. After he had signed an informed consent form, his medical and dental history were recorded. He came to a hospital emergency room a week post-trauma with the chief complaint of "mobile teeth". His release form indicated that his lower incisors had 1-2 level mobility but no dislocation was observed (although no radiographs were taken in the emergency

(c) Jaypee Brothers Medical Publishers. 2021 Open Access This article is distributed under the terms of the Creative Commons Attribution 4.0 International License (https://creativecommons.org/licenses/by-nc/4.0/), which permits unrestricted use, distribution, and non-commercial reproduction in any medium, provided you give appropriate credit to the original author(s) and the source, provide a link to the Creative Commons license, and indicate if changes were made. The Creative Commons Public Domain Dedication waiver (http://creativecommons.org/publicdomain/zero/1.0/) applies to the data made available in this article, unless otherwise stated. 
room). He claimed that his orthodontic fixed retainer had fallen during the injury (he completed a 2-year orthodontic treatment 13 months before the injury). A buccal splint composed of a rigid wire and composite was performed (Fig. 1A and B). There were no apparent changes noticed in occlusion and he was released with the recommendation of a soft diet and a follow-up appointment including splint removal after 4 weeks.

Clinical examination was then performed at our department's clinic. The mandibular incisors responded negatively to cold (Endo-frost, Coltene /Whaledent AG, Altstätten, Switzerland) and
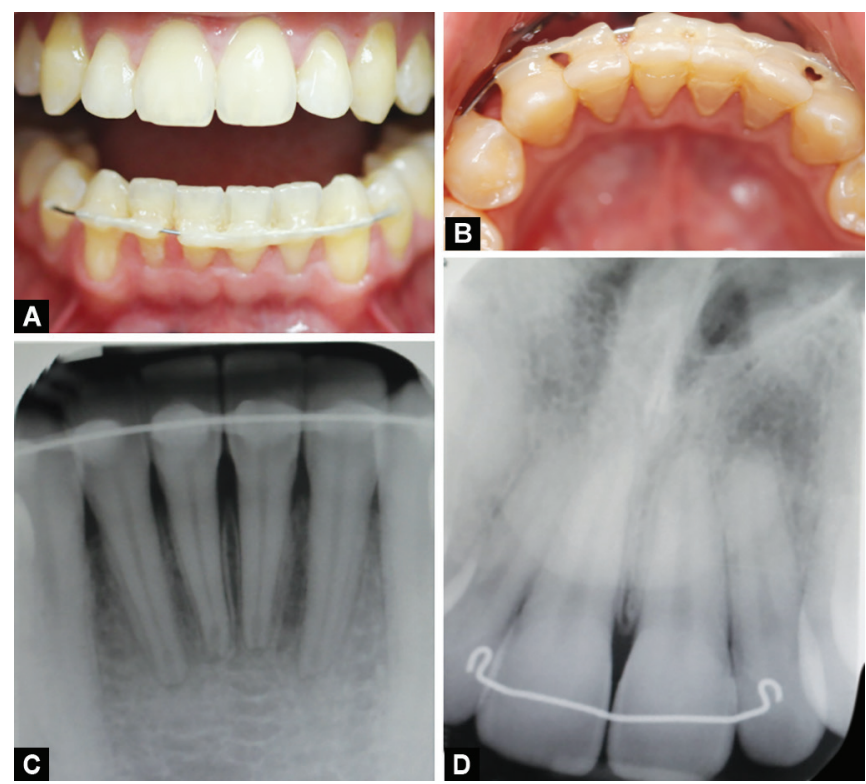

Figs. 1A-D: Initial examination: clinical (A, B) images showing intact crowns, lingual calculus, remnants of the lingual composite of an orthodontic fixed retainer, and a buccal splint. Radiographic image (C) showing an oval widening of the apical third of root canals in all four mandibular incisors. Maxillary incisors were without evidence of pathology $(A, D)$

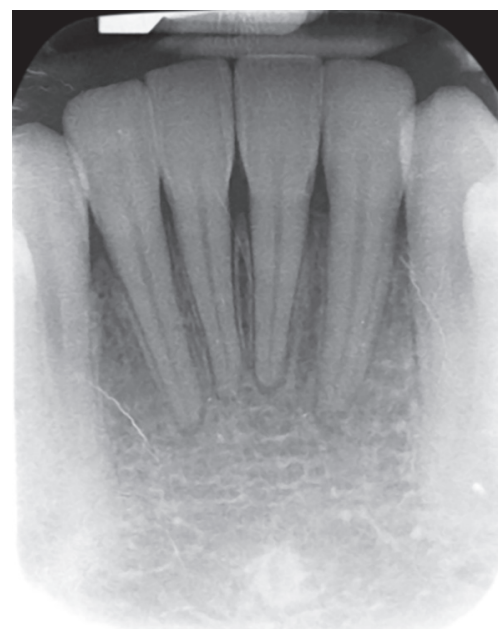

Fig. 2: Periapical radiograph of the incisors one month before injury showing no evidence of IRR.

electric pulp testing (Digitest II, Parkell Inc., NY, USA). No sensitivity to percussion or palpation was shown. Tooth mobility was not examined due to the presence of the rigid splint. Pocket depths were within normal limits. No swelling, sinus tract, or coronal color change were evident. A diagnostic periapical radiograph revealed an oval widening of the root canal spaces at the apical thirds in all four mandibular incisors. The original canal boundaries were invisible in the widened areas (Fig. 1D). A periapical radiograph of the mandibular incisors obtained from the patient's former dental clinic showed no evidence of IRR one month before the injury (Fig. 2).

To confirm the preliminary diagnosis of IRR and exclude the existence of perforations, the patient was referred for conebeam computer tomography (CBCT) imaging (Carestream 9300; Carestream Health, Rochester, NY, USA) as per relevant guidelines. ${ }^{11,12} \mathrm{CBCT}$ images confirmed the diagnosis of internal resorption, without any evidence of perforation (Fig. 3). Also, axial slices showed that all canals were long oval. ${ }^{13}$
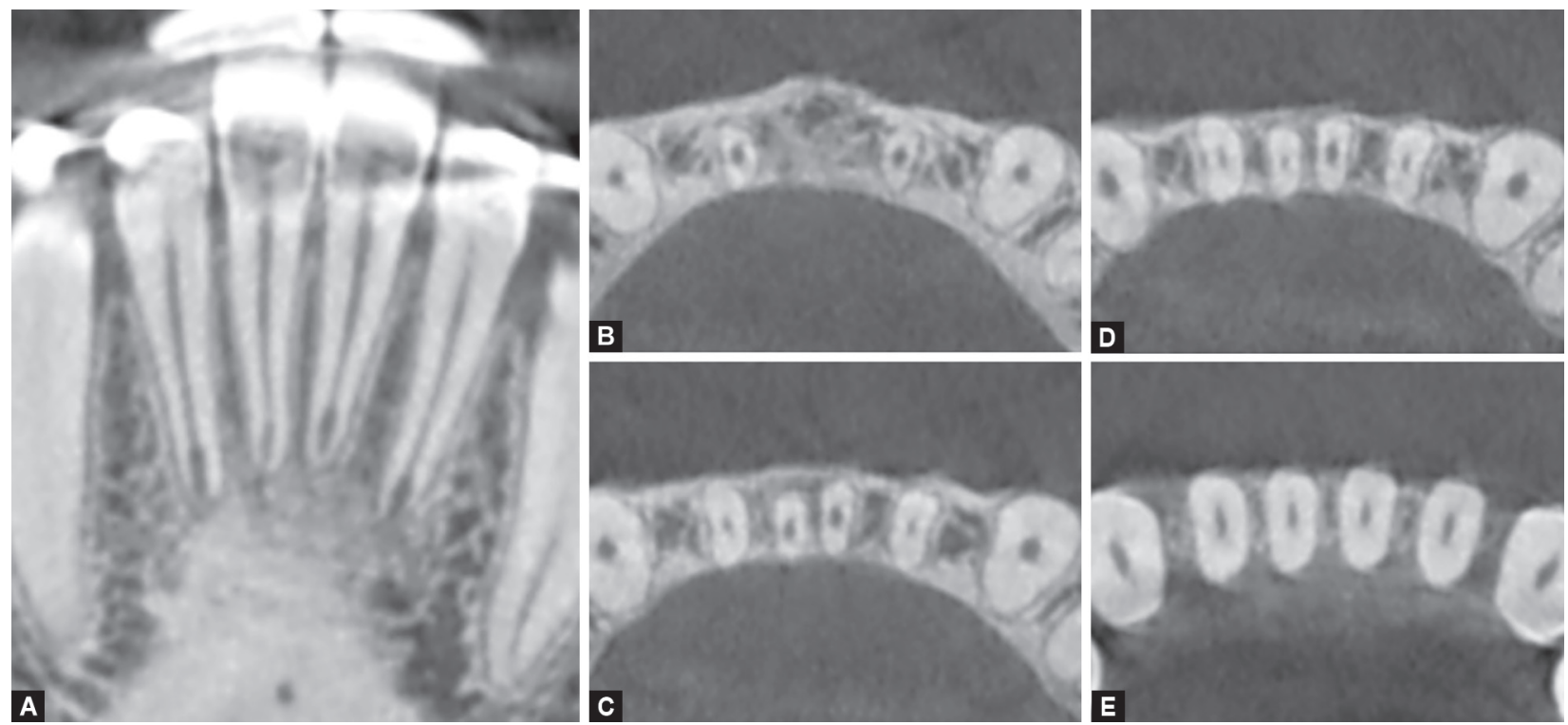

Figs. 3A-E: Small field of view CBCT images: coronal (A) and axial (in an apical to coronal advancement from $B$ to $E$ ) showing internal resorption and long oval shape of the canals. There is no evidence of canal wall perforation 


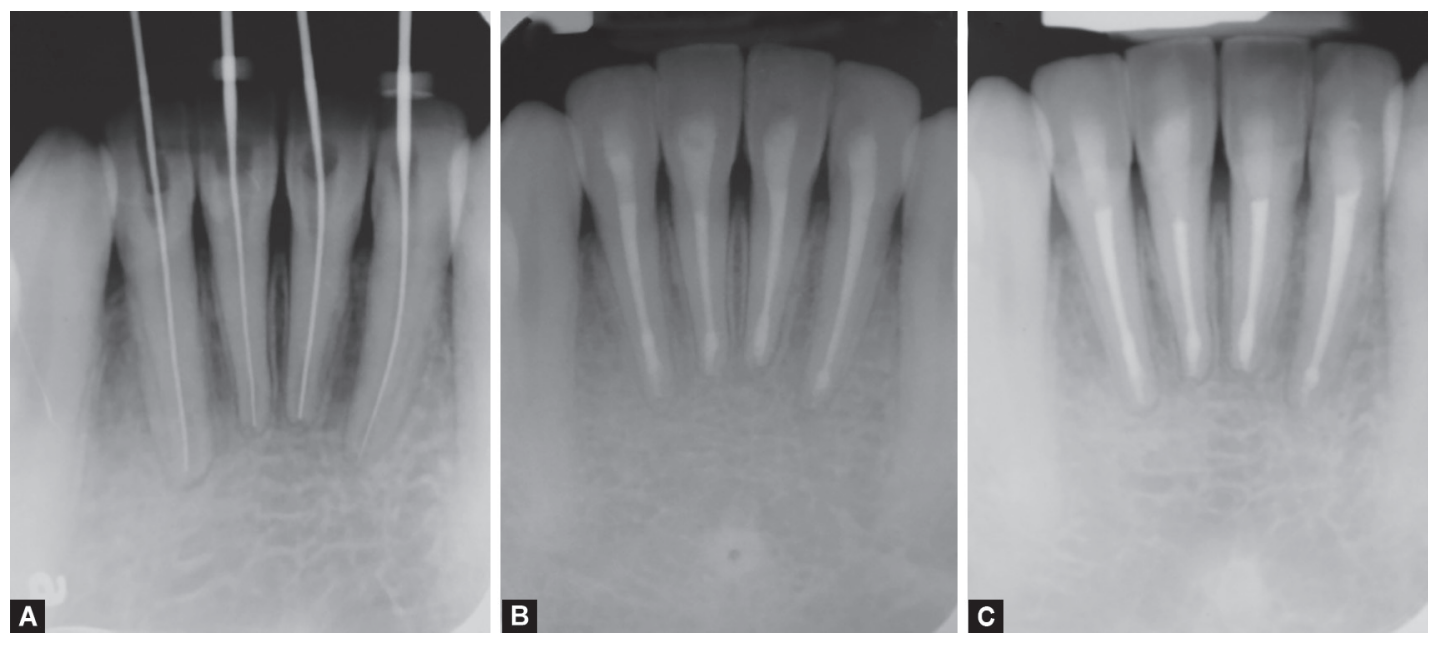

Figs. 4A-C: Root canal treatment: (A) Radiographic working length measurements, (B) Post-treatment radiograph, (C) 15-months post-trauma follow-up (10 months post-treatment) - radiograph showing no evidence of pathology

According to the dental history, clinical and radiological findings, the possible diagnoses in all four mandibular incisors were:

Periapical diagnosis: normal apical tissues, status-post subluxation.

Pulpal differential diagnosis revealed the following:

- Pulp necrosis: In this case, the IRR process was no longer active.

- Normal pulp (or partially necrotic) with an active resorption process.

In both cases, root canal treatment was indicated.

After the patient had signed an informed consent form, local anesthesia was administered with two $1.8 \mathrm{~mL}$ cartridges of $4 \%$ articaine with 1:100,000 epinephrine (Septocaine, Septodont Inc., Louisville, CO, USA) by local infiltration. The splint was removed. The rubber dam was applied with clamps on both first molars. After the access cavities were made, working lengths were obtained by an electronic apex locator (Apit 11, Osada Electronic Co., Tokyo, Japan) and a periapical radiograph (Fig. 4A). In all four incisors, the coronal and middle thirds of the root canals contained necrotic pulp tissue and there was bleeding from the apical part. The canals were widened to ISO size 20\# using stainless steel files (K-Files, Kerr dental, CA, USA). Further chemo-mechanical preparation of the root canals was made using the self-Adjusting file (SAF) system (ReDent Nova, GmbH \& Co. Kg., Berlin, Germany) size $1.5 \mathrm{~mm}$ for 4 minutes in each canal with $4 \%$ sodium hypochlorite delivery at $4 \mathrm{~mL} /$ minute rate followed by the use of XP-endo Finisher (FKG Dentaire, La Chaux-de-Fonds, Switzerland). After using the SAF system, bleeding from the canals stopped almost completely. Calcium hydroxide dressing was then placed for 3-4 weeks. The second appointment for each tooth included removal of calcium hydroxide with sodium hypochlorite and $17 \%$ ethylenediaminetetraacetic acid (EDTA) rinses with simultaneous SAF activation followed by the use of XP-endo finisher.

Obturation of the root canals was made using the combination technique that incorporated cold lateral compaction of Guttapercha and EndoSequence BC sealer (Brasseler, Savannah, GA, USA) in the apical 3-4 mm followed by warm compaction with B\&L Alpha heat carrier (B\&L Biotech, Gunpo, Korea) and Machtou pluggers (Dentsply Maillefer, Ballaigues, Switzerland). ${ }^{14,15}$

EQUIA glass ionomer (GC America Inc., Alsip, IL, USA) was used to temporize the access cavity (Fig. 4B). A 15-months post-trauma follow-up (10 months post-treatment) was done. The patient was satisfied with the result and reported no symptoms. There was no tenderness to percussion or palpation and mobility and pockets depth were within normal limits. A periapical radiograph revealed that the periodontal ligament spaces were intact and showed no evidence of pathology (Fig. 4C).

\section{Discussion}

IRR can be classified as transient or progressive. The transient form of IRR is mostly due to damage to the odontoblast or predentin layers that protect the dentin from clastic cells, ${ }^{6,8}$ while a concomitant infection leads to a more rapid and progressing variant, ${ }^{6,7,16}$ that may cause extensive damage and tooth loss. ${ }^{3}$ The progressive form is active as long as the pulp is vital apical to the resorptive area. ${ }^{10}$ Another way to classify IRR is by histologically differentiating a purely destructive inflammatory form, in which dentin is replaced by granulation tissue, from a replacement resorption form that involves repair and the deposition of metaplastic hard tissue that resembles bone or cementum. 3,6,16

In our case, it seems that the process was probably active. Pulps were necrotic in all four incisors coronal to the resorption areas but the bleeding was observed in the apical third of the canals, thereby suggesting an active blood supply to the resorptive process. Also, we could not draw any definite conclusion as to whether the resorption process was transient (and the necrotic pulp was sterile) or progressive (infected necrotic pulp), since the crowns remained intact after the trauma. In this case, the possible routes of infection of the pulp were exposed dentinal tubules, microcracks, and cementoenamel junction defects. ${ }^{3}$

Though the risk of pulp necrosis in subluxation is relatively low $^{17}$ in our case, the pulps underwent necrosis. Orthodontic treatment can also cause pulp inflammation, vascular changes, pulp canal obliteration, and pulp necrosis. ${ }^{18}$ In the present case, pulp necrosis might have been the result of accumulated trauma due to the past orthodontic treatment, subluxation, and the longstanding rigid fixation, or any combination of these factors. ${ }^{18-20}$ There are several studies regarding possible adverse sequelae of traumatized teeth followed by orthodontic treatment, but there are no reports about traumatic injuries on previously orthodontically moved teeth. ${ }^{21,22}$ Furthermore, a possible explanation for the similar 
pulpal response and IRR in all four incisors is impact distribution by the orthodontic fixed retainer that caused equal injury and almost identical resorption patterns. On the other hand, possibly, a retainer prevented a more severe luxation injury, further damage to the attachment apparatus, and external root resorption.

IRR in permanent dentition is considered a rare condition. ${ }^{2,3,5}$ Several cases of multiple IRR: either idiopathic ${ }^{5,9}$ or in association with hyperparathyroidism ${ }^{23}$ were reported in the literature. To our knowledge, this was the first case report to describe multiple IRR related to dental trauma (which was also affected by an orthodontic fixed retainer), multiple IRR limited to incisors, and the first case to present four defects of almost identical location, size, and form.

In our case, long oval canals were identified by CBCT; therefore, the SAF system was chosen due to its ability to conform to non-round canals, in contrast to the round canal preparation of most nickeltitanium (NiTi) rotary files. ${ }^{24,25}$ The XP-endo finisher file was used to improve chemo-mechanical preparation of the resorption areas. ${ }^{26}$

Calcium hydroxide was placed as an inter-appointment dressing due to its anti-microbial and tissue dissolving properties. ${ }^{27,28}$ In recent studies, SAF has shown better removal of calcium hydroxide and dentin debris than other irrigation systems in simulated IRR defects, but the results showed that remnants were still evident. ${ }^{29}$ The XP-endo finisher file had also proven effective in the removal of calcium hydroxide from these defects. ${ }^{26}$ Therefore, we utilized both file systems in an attempt to maximize cleaning of the internal resorption areas in the present case. Despite this thorough chemomechanical preparation, calcium hydroxide remnants can still be present in the resorption areas. ${ }^{30}$ Therefore, BC sealer, a calcium trisilicate-based sealer, was chosen due to its ability to better integrate with the leftover calcium hydroxide. ${ }^{31}$

Obturation of IRR defects is often performed using thermoplastic Gutta-percha injected from heat guns. ${ }^{3}$ In our case, since the defects were at the apical third of the canals, both access with the heat gun tip and the control of working length were difficult tasks. Also, cooling of injected Gutta-percha results in significant shrinkage. ${ }^{32}$ However, cold lateral compaction was shown to fill IRR defects with less Gutta-percha and more sealer than warm techniques. ${ }^{33}$ Therefore, the abovementioned combination technique was chosen due to its ability to fill the apical defects with a good Gutta-percha to sealer ratio while maintaining good obturation length control.

\section{ConcLusion}

To our knowledge, this is the first reported case of multiple IRR after dental trauma and subsequent delayed treatment. Proper evaluation of the resorptive lesions and root canal morphology is paramount for the choice of appropriate armamentarium and techniques for cleaning, shaping, and obturation.

\section{Clinical Significance}

Multiple IRR is a possible result of delayed treatment of dental trauma. The combination of the SAF and the XP-endo finisher is recommended for chemo-mechanical preparation of IRR defects in oval canals, especially at the apical third. Furthermore, the above mentioned combination technique is recommended for canal obturation of such cases.

\section{References}

1. American Association of Endodontists. Glossary of endodontic terms, 10th ed.; 2020.
2. Gunraj MN. Dental root resorption. Oral Surg Oral Med Oral Pathol Oral Radiol Endod 1999;88(6):647-653. DOI: 10.1016/S10792104(99)70002-8.

3. Patel S, Ricucci D, Durak C, et al. Internal root resorption: a review. J Endod 2010;36(7):1107-1121. DOI: 10.1016/j.joen.2010.03.014.

4. Calişkan MK, Türkün M. Prognosis of permanent teeth with internal resorption: a clinical review. Endod Dent Traumatol 1997;13(2):75-81. DOI:10.1111/j.1600-9657.1997.tb00014.x.

5. Kalender A, Oztan MD, Basmaci F, et al. CBCT evaluation of multiple idiopathic internal resorptions in permanent molars: case report. BMC Oral Health 2014;14:39. DOI: 10.1186/1472-6831-14-39.

6. Wedenberg $C$, Lindskog $S$. Experimental internal resorption in monkey teeth. Endod Dent Traumatol 1985;1(6):221-227. DOI: 10.1111/j.1600-9657.1985.tb00584.x.

7. Wedenberg C, Zetterqvist L. Internal resorption in human teeth-a histological, scanning electron microscopic, and enzyme histochemical study. J Endod 1987;13(6):255-259. DOI: 10.1016/S00992399(87)80041-9.

8. Wedenberg $C$, Lindskog $S$. Evidence for a resorption inhibitor in dentin. Scand J Dent Res 1987;95(3):205-211. DOI: 10.1111/j.16000722.1987.tb01832.x.

9. Celikten B, Uzuntas CF, Kurt H. Multiple idiopathic external and internal resorption: case report with cone-beam computed tomography findings. Imaging Sci Dent 2014;44(4):315-320. DOI: 10.5624/isd.2014.44.4.315.

10. Tronstad L. Root resorption-etiology, terminology and clinical manifestations. Endod Dent Traumatol 1988;4(6):241-252. DOI: 10.1111/j.1600-9657.1988.tb00642.x.

11. American Association of Endodontists (AAE) and American Academy of Oral and Maxillofacial Radiology (AAOMR) joint position statement: use of cone beam computed tomography in endodontics 2015 Update. Oral Surg Oral Med Oral Pathol Oral Radiol 2015;120(4):508512. DOI: 10.1016/j.0000.2015.07.033.

12. Patel S, Brown J, Semper Metal. European Society of endodontology position statement: use of cone beam computed tomography in endodontics: European Society of Endodontology (ESE) developed by. Int Endod J 2019;52(12):1675-1678. DOI: 10.1111/ iej.13187.

13. Wu MK, R'Oris A, Barkis D, et al. Prevalence and extent of long oval canals in the apical third. Oral Surg Oral Med Oral Pathol Oral Radiol Endod 2000;89(6):739-743. DOI: 10.1067/moe.2000.106344.

14. Solomonov $M$, Itzhak JB, Levin A, et al. Successful orthograde treatment of dens invaginatus Type 3 with a main C-shaped canal based on cone-beam computed tomography evaluation. J Conserv Dent 2016;19(6):587-590. DOI: 10.4103/0972-0707.194034.

15. Shemesh A, Ben Itzhak J, Solomonov M. Minimally invasive treatment of Class 4 invasive cervical resorption with internal approach: a case series. J Endod 2017;43(11):1901-1908. DOI:10.1016/j. joen.2017.04.026.

16. Heithersay GS. Management of tooth resorption. Aust Dent J 2007;52(1 Suppl):S105-S121. DOI: 10.1111/j.1834-7819.2007. tb00519.x.

17. Andreasen FM, Pedersen BV. Prognosis of luxated permanent teeth-the development of pulp necrosis. Endod Dent Traumatol 1985;1(6):207-220. DOI: 10.1111/j.1600-9657.1985.tb00583.x.

18. von Böhl M, Ren Y, Fudalej PS, et al. Pulpal reactions to orthodontic force application in humans: a systematic review. J Endod 2012;38(11):1463-1469. DOI: 10.1016/j.joen.2012.07.001.

19. Nasjleti CE, Castelli WA, Caffesse RG. The effects of different splinting times on replantation of teeth in monkeys. Oral Surg Oral Med Oral Pathol 1982; 53(6):557-566. DOI: 10.1016/00304220(82)90340-1.

20. Hamilton RS, Gutmann JL. Endodontic-orthodontic relationships: a review of integrated treatment planning challenges. Int Endod J 1999;32(5):343-360. DOI: 10.1046/j.1365-2591.1999.00252.x.

21. Brin I, Ben-Bassat $Y$, Heling I, et al. The influence of orthodontic treatment on previously traumatized permanent incisors. Eur J Orthod 1991;13(5):372-377. DOI: 10.1093/ejo/13.5.372. 
22. Bauss O, Schäfer W, Sadat-Khonsari R, et al. . Influence of orthodontic extrusion on pulpal vitality of traumatized maxillary incisors. J Endod 2010;36(2):203-207. DOI: 10.1016/j.joen.2009.10.025.

23. Nagaraj E, Kaur RP, Raghuram PH, et al. Multiple internal resorption in permanent teeth associated with hyperparathyroidism. Indian J Dent Res 2013;24(1):128-131. DOI: 10.4103/0970-9290.114917.

24. Solomonov M, Paqué $F$, Kaya $S$, et al. Self-adjusting files in retreatment: a high-resolution micro-computed tomography study. J Endod 2012;38(9):1283-1287. DOI: 10.1016/j.joen.2012.06.019.

25. Solomonov M. Eight months of clinical experience with the selfadjusting file system. J Endod 2011;37(6):881-887. DOI: 10.1016/j. joen.2011.02.036.

26. Ulusoy ÖI, Savur IG, Alaçam T, et al. The effectiveness of various irrigation protocols on organic tissue removal from simulated internal resorption defects. Int Endod J 2018;51(9):1030-1036. DOI: 10.1111/ iej.12919.

27. Hasselgren G, Olsson B, Cvek M. Effects of calcium hydroxide and sodium hypochlorite on the dissolution of necrotic porcine muscle tissue. J Endod 1988;14(3):125-127. DOI: 10.1016/S00992399(88)80212-7.

28. Bystrom A, Claesson R, Sundqvist G. The antibacterial effect of camphorated paramonochlorophenol, camphorated phenol, and calcium hydroxide in the treatment of infected root canals. Endod Dent Traumatol 1985;1(5):170-175. DOI: 10.1111/j.1600-9657.1985. tb00652.x.

29. Topçuoglu HS, Akti A, Düzgün $S$, et al. Effectiveness of different irrigation procedures for removal of dentin debris from a simulated internal resorption cavity. Int J Artif Organs 2015;38(3):165-169. DOI: 10.5301/ijao.5000398.

30. Kfir A, Blau-Venezia N, Goldberger T, et al. Efficacy of self-adjusting file, XP-endo finisher and passive ultrasonic irrigation on the removal of calcium hydroxide paste from an artificial standardized groove. Aust Endod J 2018;44(1):26-31. DOI: 10.1111/aej.12204.

31. Uzunoglu-ÖzyürekE, Erdoğan Ö, Aktemur Türker S. Effect of calcium hydroxide dressing on the dentinal tubule penetration of 2 different root canal sealers: a confocal laser scanning microscopic study. J Endod 2018;44(6):1018-1023. DOI: 10.1016/j.joen.2018.02.016.

32. Lottanti S, Tauböck TT, Zehnder M. Shrinkage of backfill guttapercha upon cooling. J Endod 2014;40(5):721-724. DOI: 10.1016/j. joen.2013.09.043.

33. Gencoglu N, Yildirim T, Garip Y, et al. Effectiveness of different guttapercha techniques when filling experimental internal resorptive cavities. Int Endod J 2008;41(10):836-842. DOI: 10.1111/j.13652591.2008.01434.x. 